\title{
"Em busca do astronauta perdido": um experimento na formação inicial de professores de matemática envolvendo Geometria Analítica \& História em Quadrinhos
}

\section{"In Search of the Lost Astronaut": an experiment in the initial formation of mathematics teachers involving Analytical Geometry \& Comics}

Rodrigo Sychocki da Silva1; Mayara Becker Oliveira da Silva1; João Carlos Tavares Pereira1; Leandro Carlos Blum ${ }^{1}$

\section{RESUMO}

O artigo apresenta e faz uma reflexão sobre um experimento de ensino ocorrido no primeiro semestre de 2017 em um curso de formação inicial de professores de matemática, numa universidade pública do Rio Grande do Sul. Em linhas gerais a proposta relacionou matemática, história em quadrinhos e tecnologias digitais. A partir dos conceitos de zona de risco e zona de conforto encontrados e explorados na literatura, foi construída e aplicada uma proposta de ensino, de caráter experimental, numa disciplina de graduação. A título de inferência, os resultados e reflexões realizadas posteriores ao experimento contribuem na área de Educação Matemática, destacando-se os desafios inerentes do fazer docente, já presentes na formação inicial do professor de matemática.

Palavras-chave: Experimentação; Formação de Professores de Matemática; Tecnologias Digitais; Zona de Conforto; Zona de Risco.

\begin{abstract}
The article presents and makes a reflection on an educational experiment that took place in the first semester of 2017 in an initial training course of mathematics teachers, at a public university in Rio Grande do Sul. In general, the proposal related mathematics, comics and digital technologies. From the concepts of risk zone and comfort zone found and explored in the literature, a proposal of teaching, of experimental character, was constructed and applied in a subject of graduation. As an inference, the results and reflections carried out after the experiment contribute to the area of Mathematics Education, highlighting the inherent challenges of teacher making, already present in the initial formation of the mathematics teacher.
\end{abstract}

Keywords: Experimentation; Teacher Training in Mathematics; Digital Technologies; Comfort Zone; Risk Zone.

\footnotetext{
${ }^{1}$ UFRGS - Universidade Federal do Rio Grande do Sul, Porto Alegre/RS - Brasil
} 


\section{INTRODUÇÃO}

No currículo do curso de licenciatura em Matemática da Universidade Federal do Rio Grande do Sul uma das últimas disciplinas a ser cursada (sexto semestre na modalidade diurna e oitavo semestre na modalidade noturno do curso) chama-se Educação Matemática e Tecnologia. No plano de ensino da disciplina, documento disponibilizado aos estudantes no início do semestre, apresenta-se como meta que a mesma oportunize:

Análise e proposta de utilização de diferentes softwares para o ensino e aprendizagem da Matemática na escola, acompanhada de prática pedagógica. Análise de sites Web na área de Educação Matemática e suas possíveis utilizações no dia a dia da sala de aula. Construção de referencial teórico na área de tecnologia informática aplicada à Educação Matemática. (UFRGS, 2017, p.1)

A partir de uma reflexão sobre o plano de ensino espera-se um entendimento, por parte do professor regente, de que a turma que cursará a disciplina já esteja preparada para ensinar tópicos de matemática, uma vez que nesta etapa do curso o estudante já percorreu e vivenciou as disciplinas práticas de ensino da matemática. Então, considera-se apropriado que

Inspirados na pesquisa de Richit e Silva (2014), a proposta apresentada aos estudantes da disciplina em 2017 era de criar e executar um experimento de ensino que utilizasse o software gráfico Winplot. O software, de característica livre e irrestrita, apresenta inúmeras funcionalidades, dentre as quais fazem parte o ensino e manipulação de objetos da geometria analítica. Richit e Silva (2014) dissertam sobre um experimento de ensino ocorrido num curso superior de Licenciatura em Matemática e inferem que o uso do software de fato ajudou na compreensão e construção de conceitos matemáticos sobre superfícies quádricas.

Assim constrói-se a problemática exposta no presente artigo. Com a proposta de criar e executar um experimento de ensino num curso de formação inicial de professores de matemática, o software Winplot foi usado na elaboração de atividades que oportunizassem o estudo de algum tópico de matemática. Neste caso, o tópico escolhido para ser abordado foi geometria analítica e junto com o software foram usadas histórias em quadrinhos, além de um ambiente virtual (Wiki do PBWorks) para organizar e divulgar as atividades.

A experimentação ocorreu in loco, onde a sala de aula da própria disciplina de Educação Matemática e Tecnologia em 2017/1 na universidade foi o espaço usado para o debate e realização das atividades. Após a realização do experimento, os participantes da turma foram convidados a fazer uma análise crítica da proposta, destacando potencialidades, pontos positivos e negativos que observaram.

Portanto, o presente artigo pretende além relatar sobre as atividades, expor uma fundamentação teórica entendida como necessária à construção e execução da proposta. A proposta sobre o uso das tecnologias em sala de aula baseia-se teoricamente nos conceitos de Zona de Risco e Zona de Conforto, apresentadas por Borba e Penteado (2001). Além disso, mostra-se por meio da revisão de literatura, trabalhos e pesquisas confluentes a ideia exposta neste artigo. Após, apresentam-se os materiais e métodos utilizados durante o experimento. Na forma de um produto educacional disponibiliza-se o endereço eletrônico onde é possível acessar as atividades, com o objetivo de servir como inspiração aos interessados em aprimorar os seus conhecimentos para o exercício da prática docente em matemática. As análises sobre o experimento são feitas a partir de recortes das impressões e observações dos demais participantes, à luz das ideias debatidas na fundamentação 
teórica. Por fim, expõem-se perspectivas sobre o experimento realizado, a partir de lições e reflexões decorrentes do exercício prático.

\section{ZONA DE RISCO \& ZONA DE CONFORTO: UM APORTE TEÓRICO}

A realização das atividades expostas no presente artigo mobilizou os envolvidos quanto ao desafio de responder a indagação: como sair da zona de confronto e propor uma atividade que atenda as expectativas e mobilize discentes para o entendimento do software, propiciando que este seja objeto de reflexão por parte do aluno e, que com isso ele possa ser utilizado futuramente nas atividades profissionais.

Para a elaboração de uma proposta de ensino reflexiva é necessário que o professor tenha em mente o enfrentamento das dificuldades, tais como apresentam Borba e Penteado (2001):

é difícil de negar o potencial que uma zona de risco tem de provocar mudanças e impulsionar desenvolvimento. Porém, é um caminho árduo para o professor. Parece mais fácil tentar enquadrar a TI nas velhas rotinas (grifo nosso). Mas será que não há como enfrentar essas dificuldades? (BORBA, PENTEADO, 2001, p. 66)

Borba e Penteado (2001) em sua obra apresentam reflexões por meio de resultados de pesquisas que direcionam para uma resposta afirmativa quanto ao questionamento que é proposto. Ao mesmo tempo é necessário observar que, "não é possível manter-se na zona de riscos sem se movimentar em busca de novos conhecimentos" (BORBA, PENTEADO, 2001, p. 63). A zona de risco é um caminho trabalhoso para o professor, e que oportuniza construir mudanças nas ações em sala de aula. Concordamos com os autores quando afirmam que "acreditamos que o engajamento de professores em redes de trabalho é uma possibilidade de expandir essa forma de agir e pensar e, consequentemente, provocar mudanças na educação escolar." (BORBA, PENTEADO, 2001, p. 70).

O termo "velhas rotinas" (BORBA e PENTEADO, 2001) grifado na citação anterior merece uma reflexão e destaque para o presente texto. Dentre os diversos modos de usar o computador em sala de aula e as interconexões do uso com as "velhas rotinas", os autores trazem como reflexão o fato de que mesmo usando o computador nas aulas, o método de ensino é caracterizado como exclusivamente expositivo. Nesse caso, o uso da tecnologia é um complemento desse método de ensino, o computador seria uma ferramenta para apenas expor o conteúdo, porém de outra forma. Para explicar essa ação Borba e Penteado (2001) apresentam a seguinte reflexão:

Aula expositiva, seguida de exemplos no computador, parece ser uma maneira de domesticar (grifo nosso) essa mídia. A forma de evitar isso seria a escolha de propostas pedagógicas que enfatizem a experimentação, visualização, simulação, comunicação eletrônica e problemas abertos. (BORBA, PENTEADO, 2001, p. 88)

O termo "domesticar" está colocado pelos autores incitando que uma abordagem talvez considerada menos proveitosa, em termos educacionais, seria usar o computador para expor o conteúdo se assim o fizesse do mesmo modo sem o computador. Neste caso, no entendimento dos autores, não seria profícuo inserir o uso do computador nas aulas. É válido mencionar que o professor precisa ser consciente de que a tecnologia pode proporcionar a reorganização do pensamento por parte dos sujeitos que a usam. Logo, considera-se importante que o professor tenha conhecimento de como utilizar, quais softwares e saiba das possibilidades que o uso das mídias pode oportunizar em sala de 
aula. Portanto, para que o professor saia da zona de conforto, a partir dos aportes teóricos analisados, ele precisa estar constantemente atualizando-se a respeito das inovações educacionais.

Logo, constata-se na dicotomia "zona de risco" e "zona de conforto" a existência de um espaço para debate na Educação Matemática. As provocações e ideias apresentadas por Borba e Penteado (2001) convidam para uma reflexão: Até que ponto uma aula com o uso do computador de fato se diferencia de uma aula que não faça o uso do computador? No experimento de ensino explorado nesse artigo, a atividade criada e que envolvia geometria analítica, histórias em quadrinhos e tecnologias almejava entre outros objetivos, descentrar e fazer nós, autores dessas reflexões, sair da zona de conforto. Ao arriscar, experimentar e propor momentos de investigação objetivou-se vivenciar na prática o que é estar na zona de risco.

\section{REVISÃO DE LITERATURA}

A revisão de literatura exposta nesta seção objetiva apresentar um recorte das pesquisas que versam sobre o uso de histórias em quadrinhos e tecnologias digitais no ensino da matemática. Esta seção trata de um movimento, que é uma importante ação na Educação Matemática, que discute e apresenta possibilidades a partir de pesquisas e reflexões realizadas no campo teórico e prático. Essencialmente, num primeiro momento serão apresentadas pesquisas que utilizaram histórias em quadrinhos (HQs) como um elemento no ensino e para a discussão de conceitos matemáticos e no segundo momento será explanado o campo de pesquisas que usaram as tecnologias digitais, em especial o software Winplot, o qual foi também usado no presente experimento.

As pesquisas consultadas ocorreram com os mais diversos públicos e modalidades de ensino, o qual nos permite inferir sobre a pertinência em debater questões aderentes ao assunto. $O$ espectro e alcance das pesquisas mostradas nesta seção também permitem refletir o quanto a iniciativa e o debate da temática proposta no artigo é aderente ao curso de formação inicial de professores de matemática e insere-se como emergente e necessário.

Pereira (2010) em sua pesquisa com estudantes da Licenciatura em Matemática da Universidade Estadual do Ceará disserta constata que o trabalho cooperativo entre os estudantes seja algo que oportuniza a construção de conhecimentos. Neste caso, na pesquisa, o uso das HQs além de incentivar a criatividade e imaginação, oportunizou que novas formas de expressão para os conceitos surgissem, por meio das discussões entre os pares na sala de aula. Estendendo-se para o nível fundamental de ensino, Parmegiani (2012) constata como resultados em sala de aula fatos que são aderentes ao que expõe Pereira (2010). Neste caso, a reflexão incita que:

Os alunos aplicam-se em todas as etapas do trabalho, desde a pesquisa até a produção propriamente dita. É visível, também, a alegria dos grupos ao expor seus trabalhos à classe e o empenho em justificar textos ou imagens. 0 rodízio dos trabalhos entre os grupos socializa, também, as técnicas referentes à tecnologia empregada por cada um. Os estudantes têm um conhecimento de informática que, muitas vezes, surpreende e todos aprendem, professor e alunos. A situação também deve ser aproveitada para uma orientação mais detalhada sobre o que é e como se faz uma pesquisa. Depois de uma maior familiaridade da turma com a atividade como um todo, a mesma pode ser antecedida, em outros momentos, da redação de um projeto de pesquisa. (PARMEGIANI, 2012, p.6) 
Em aderência com a citação anterior, Miskulin et al (2006, p.8) em pesquisa realizada também com crianças e fazendo uso de HQs com tecnologias digitais constatou que sobre a criação de estratégias próprias, as crianças "reavaliaram constantemente os objetivos a serem alcançados, transpuseram conhecimentos anteriores na composição de suas heurísticas, enfim, recorreram a hipóteses e conjecturas sobre a realidade em que estão inseridos". Isso indica que oportunizar momentos de criação e exploração de ideias matemáticas por meio de HQs com auxílio das tecnologias digitais seja profícuo à construção de conceitos.

No que se refere à formação continuada de professores, Andrade et al (2013) em sua pesquisa observou e analisou a formação de professores na França. Fazendo-se uso das HQs os pesquisadores constataram que:

Consideramos que a diversidade das narrativas apresentadas, a reflexão e o debate entre os alunos sobre situações representadas nos quadrinhos, a proposição de soluções para os problemas levantados, a interação entre os estudantes em formação contribuíram para uma tomada de consciência com base em situações concretas, tendo por objetivo reduzir a distância entre o professor e o aluno idealizado e o professor e o aluno real. (ANDRADE et al, 2013, p.153)

A dicotomia entre aluno idealizado e aluno real mencionada na citação anterior oportuniza refletir quais são os objetivos do professor ao propor determinado encaminhamento das atividades. A distância entre professor e aluno, na sala de aula, pode ser minimizada quando se pensa a sala de aula enquanto lugar para a experimentação. Nesse caso, o uso de HQs em práticas de ensino, segundo Andrade et al (2013) se mostra como uma alternativa para envolver e convidar os discentes à construção do conhecimento, o que, portanto, é convergente ao pensamento cooperativo na sala de aula, ao qual Cunha (2009) esclarece que:

(...) é possível criar soluções didáticas alternativas. Tanto o uso de quadrinhos quanto o da informática se mostraram instrumentos capazes de mobilizar a atenção dos estudantes, assim, oferecendo ao professor uma possibilidade de trabalhar em conjunto com o estudante, melhorando a comunicação entre eles. (CUNHA, 2009, p. 51)

Na pesquisa de Moraes (2009) nota-se uma reflexão importante e aderente ao que Cunha (2009) expõe anteriormente. O trabalho entre pares na sala de aula oportuniza criar a partir de experimentações, reflexões e conhecimentos que talvez sem o trabalho cooperativo não fossem possíveis de alcançar. A autora contribui salientando que:

Neste contexto, também são trabalhos o senso crítico, a capacidade de fazer análise, identificar relações e conteúdos, além de saber demonstrar através da escrita o pensamento que desenvolveram e de que forma compreenderam as definições e aplicações dos conceitos matemáticos, todas estas questões puderam ser abordadas e trabalhadas com os estudantes em sala de aula. (MORAES, 2009, p.38)

Sobre o uso do software Winplot as pesquisas, consultadas e expostas aqui, mostram que o mesmo permitiu aos participantes dos experimentos de ensino novas formas de manipulação e construção de conceitos matemáticos. Sobre o uso do software Winplot no ensino de Álgebra Linear, Silva (2017) argumenta:

O uso de recursos computacionais como ferramenta didática pode, além de motivar as aulas de matemática, facilitar a formação de conceitos e aprofundar o entendimento do conteúdo através da exploração e integração dos aspectos gráficos, geométricos, numéricos e analíticos. (SILVA, 2017, p.1) 
A partir do exposto anteriormente é possível inferir que o uso de tecnologias digitais, em particular do software Winplot, oportuniza ir além do que se pode alcançar em aulas que aconteçam sem o recurso tecnológico. A importância entre a integração dos aspectos e elementos permite que os sujeitos envolvidos organizem e reestruturem formas e pensamentos. Logo, tais elementos mostramse necessários para a construção do conhecimento matemático.

A curiosidade, interesse e empenho são características mencionadas por Lourenço (2017) em sua pesquisa que envolveu o uso do Winplot no estudo das funções quadráticas. Tais características são extensivas para todos os níveis de ensino, ou seja, desde o nível básico até o superior, nota-se em relatos e análises de pesquisas que atividades que mobilizam o sujeito e de alguma forma o retiram da zona de conforto (vide seção anterior do artigo), são atividades com aprendizagem mais profícua. Richit e Silva (2014) dissertam que a exploração do assunto superfícies quádricas num curso de Geometria Analítica na Licenciatura em Matemática foi ressignificado a partir da inserção do recurso tecnológico em sala de aula. Silva et al (2012) contribui com reflexões a partir das dificuldades apresentadas no estudo de gráficos na matemática, o que desencadeou uma série de reflexões a partir do uso do software Winplot e uma experimentação de ensino com estudantes do ensino médio e superior.

Para finalizar, tratando-se de uma revisão e reflexão sobre a literatura, é importante que o professor de matemática, em formação inicial ou continuada, tenha consciência sobre as consequências de suas ações, sejam elas no exercício profissional ou em formação. O ensino da matemática, quando feito por meio do uso de softwares, é permeado de desafios. A seção anterior abordou a dicotomia entre zona de risco e zona de conforto, logo, é válido considerar que usar software em sala de aula tratase de uma constante inserção do professor no espaço ou zona de risco. Portanto, as reflexões e pesquisas consultadas, mostram-se como alternativas, nas quais o uso de software em sala de aula constitui-se num conjunto de iniciativas e práticas docentes que podem ser replicadas, aperfeiçoadas e continuadas.

\section{MATERIAIS E MÉTODOS DO EXPERIMENTO}

Inicialmente a proposta consistiu que o grupo de licenciandos matriculados na disciplina de Educação Matemática e Tecnologia em 2017/1 (total de 13 estudantes) elaborasse, a partir de uma exploração no software Winplot, um material com experimentação didática e que contemplasse: apresentação do software; exploração das janelas 2D e 3D e um experimento de ensino. Ao todo, ocorreram três momentos de experimentação conduzidos pelos estudantes da disciplina de Educação Matemática e Tecnologia, pois a turma se dividiu em três grupos com um quantitativo quase homogêneo. 0 presente texto trata de apresentar e refletir sobre um dos momentos, o qual foi feito o uso do Winplot e das HQs na condução das atividades. A título de conhecimento, o Winplot é um software livre e sua interface está mostrada na Figura 1 a seguir. 


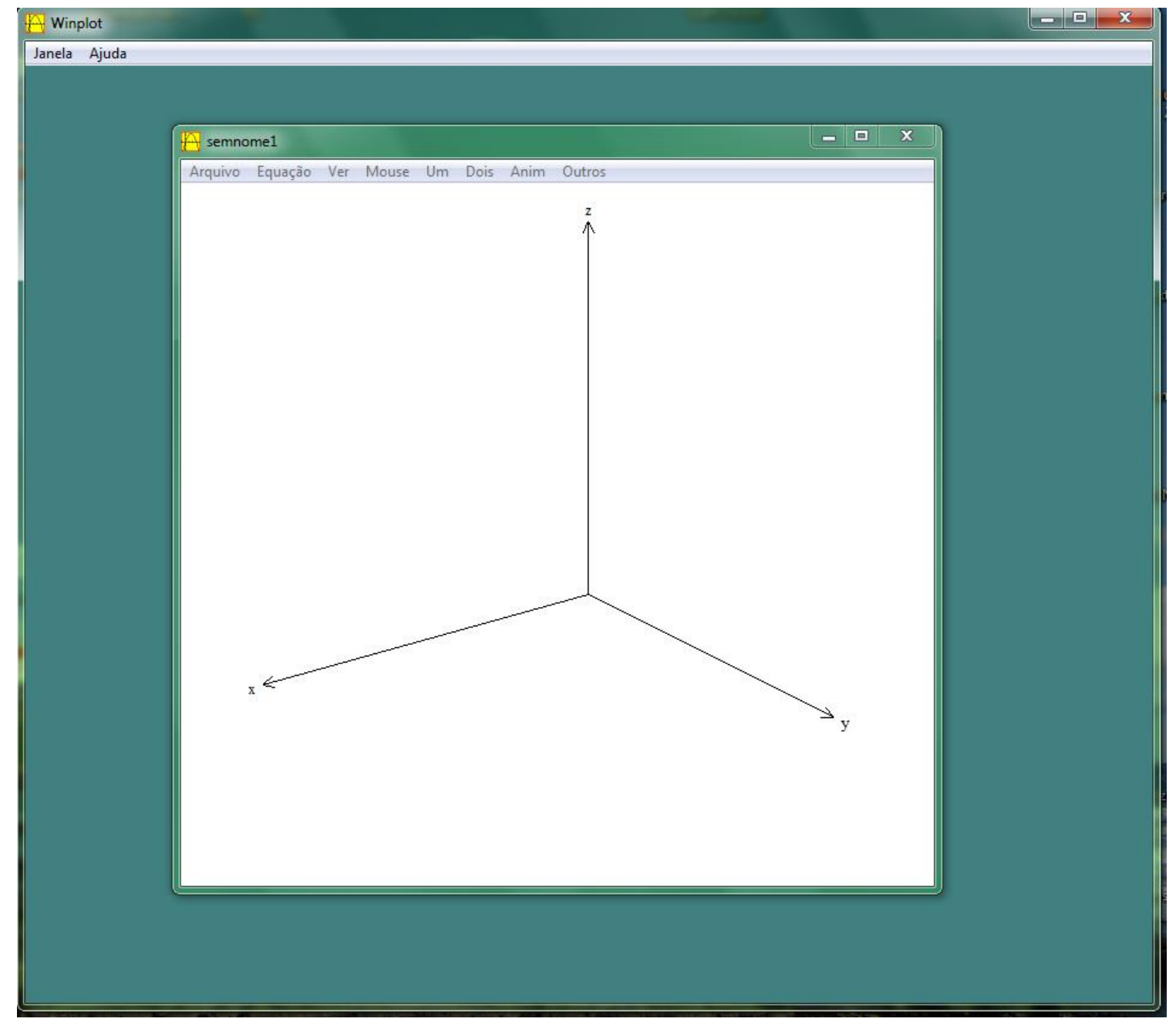

Figura 1: Interface do software Winplot, com ênfase na janela de visualização 3D.

Fonte: Autores.

A partir dos debates e reflexões até então feitos na disciplina, pensou-se em relacionar três áreas distintas: a tecnológica, tal como descrita previamente e alinhada com o que a disciplina Educação Matemática e Tecnologia propõe na graduação e mencionada na introdução desse texto; a matemática, representada pelo conhecimento de cada participante na forma de teoremas, fórmulas, tendo a possibilidade de agregar experiência à dinâmica proposta na disciplina e, por fim; a arte, que aqui relaciona as duas anteriores por meio de narrativas em HQs. Desse modo, foi criado pelo grupo de estudantes, autores do presente texto, um material para o experimento, o qual intitula o este artigo: "Em busca do astronauta perdido".

Como forma de organizar e disponibilizar o material para um número amplo de interessados na temática, os quais podem ser professores em formação inicial ou continuada, ou até mesmo estudantes do nível básico; foi organizado um site $e^{2}$, utilizando-se a plataforma do PBWorks ${ }^{3}$ para hospedagem. No site é possível acessar todos os materiais e encaminhamentos pensados para a execução da proposta. O grupo proponente organizou o material na forma de hiperlinks, os quais o usuário pode visitar as páginas e demais materiais complementares sobre o assunto. Na Figura 2 mostra-se o layout da página principal do site.

\footnotetext{
2 Disponível em: http://winplotsalavirtual20171.pbworks.com/w/page/118159977/Entendendo\%200\%20WinPlot Acesso em março de 2018.

${ }^{3}$ Disponível em http://www.pbworks.com/ Acesso em março de 2018.
} 


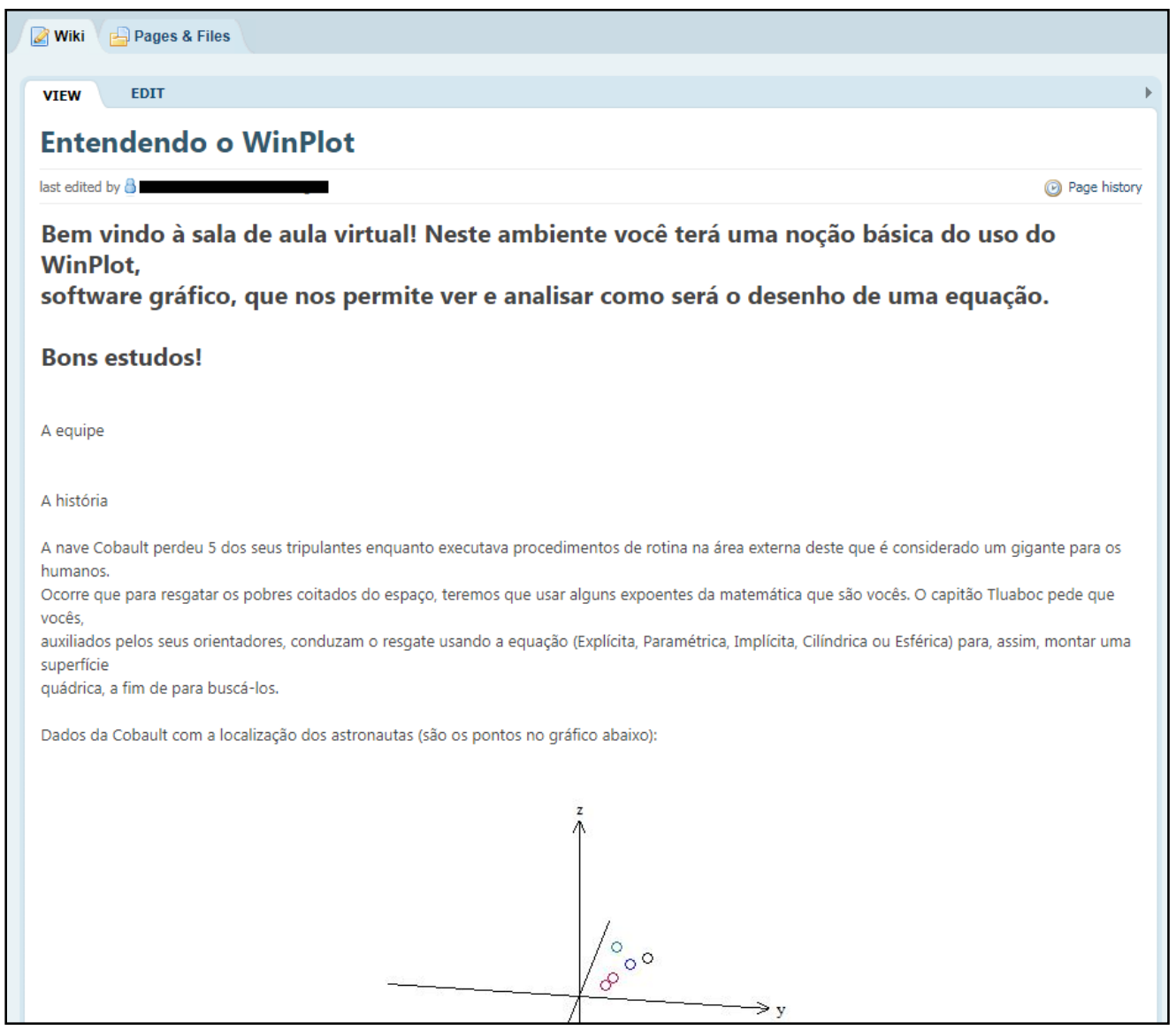

Figura 2: Layout do site criado no Wiki para organizar e disponibilizar a proposta.

Fonte: Autores.

A HQ surgiu no experimento como uma forma de dialogar com os demais participantes da atividade em sala de aula. O material, também disponibilizado no site, consistia em apresentar ideias, estimular a imaginação e debates matemáticos, as quais de alguma forma sugeriam que fosse feita uma transposição dos problemas propostos no PBWorks para o software Winplot. Na Figura 3 mostra-se uma sequência de quatro quadros envolvendo uma discussão sobre coordenadas no espaço tridimensional e que tem relação com a atividade que envolve a nave de resgate Cat's. Novamente, menciona-se que é possível encontrar todo o material da atividade na página do PBWorks informada anteriormente.

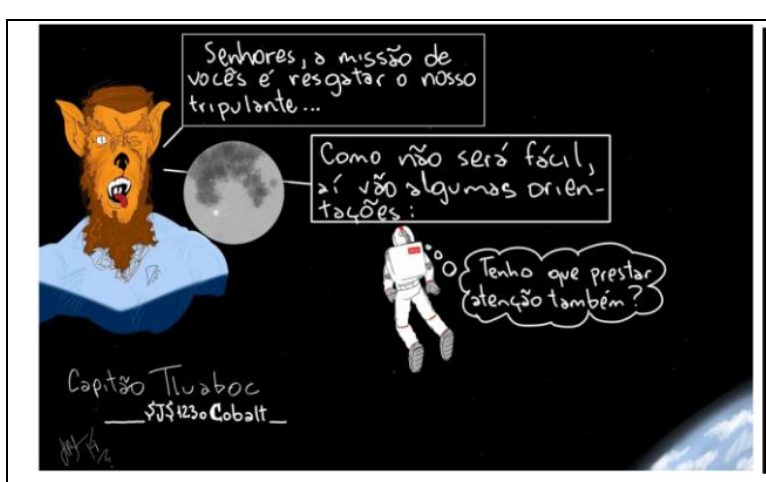

Quadro 1

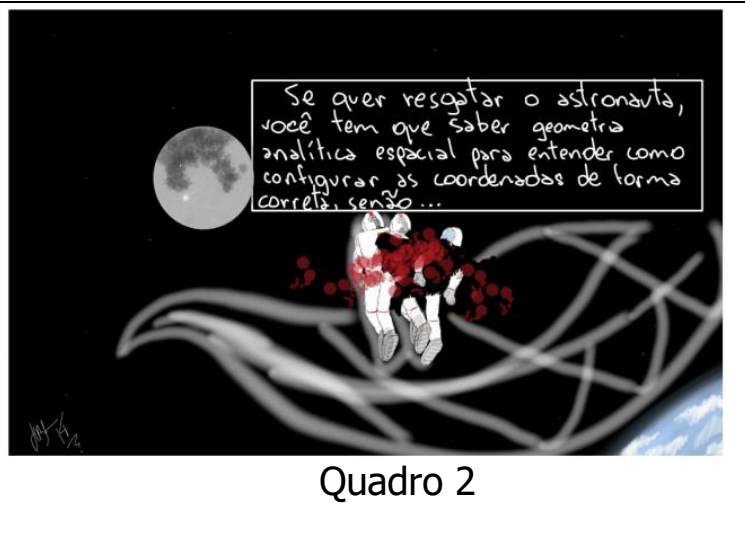




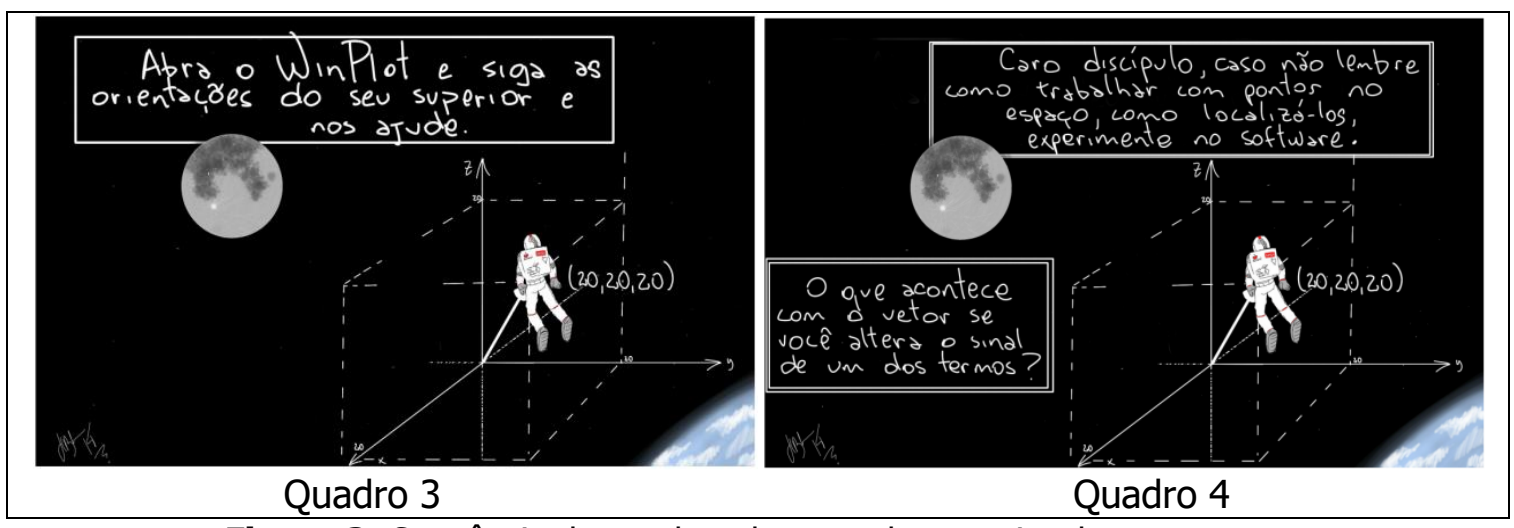

Figura 3: Sequência de quadros destacando o roteiro do astronauta.

Fonte: Autores.

Para finalizar, a atividade tinha como objetivo utilizar o software Winplot, dentro do campo imaginativo, para resgatar astronautas, já que estes estavam a "deriva" no espaço. O grupo proponente tinha a consciência sobre a existência de um longo caminho entre "imaginar" uma situação e inseri-la em um contexto educacional. Portanto, houve um preparo de quase duas semanas em que o material foi confeccionado, foram criados personagens, foi pensada uma lógica de inclusão do conteúdo de Geometria Analítica e também como utilizar o software Winplot para que a tarefa se tornasse atrativa não apenas para o momento de apresentação, mas para que se constituísse em um material com possível reuso no futuro, pelo discente durante sua atuação como docente em sala de aula.

Durante o momento da aplicação das atividades, os demais estudantes da disciplina foram alocados nos computadores do laboratório de informática da universidade, de forma que a realização das tarefas poderia ocorrer individual ou coletivamente. Ao longo do momento de explanação, o grupo condutor das discussões organizava as ideias e debatia sobre as possibilidades de "resgate" dos possíveis astronautas. Dessa maneira, estimulava-se que todos os partícipes contribuíssem com ideias e soluções para as atividades, tornando a aula de experimentação um momento de construção e argumentação coletiva. Ao final da proposta, que teve duração de uma hora e quarenta minutos, os estudantes participantes do experimento, excetuando-se os proponentes da atividade, foram convidados a fazer uma análise crítica sobre a experiência vivenciada. A seção a seguir trata de expor e analisar, à luz dos fundamentos teóricos expostos no texto, os discursos produzidos em tais falas.

\section{ANÁLISES E REFLEXÕES PÓS-EXPERIMENTAÇÃO}

Após a realização da dinâmica de aula envolvendo a execução do plano de atividades proposto, os demais participantes da disciplina foram convidados a fazer uma reflexão na forma de uma análise crítica sobre a experimentação. A iniciativa visava estimular a criticidade e o olhar dos futuros professores de matemática quanto à produção e uso de diferentes materiais nas aulas de matemática. $\mathrm{Na}$ Tabela abaixo se apresenta um recorte das reflexões produzidas pelos participantes, sendo estes os que participaram como "estudantes" no experimento. Os grifos em destaque sinalizam passagens que serão exploradas à luz do debate teórico feito anteriormente. 
Tabela 1: Recortes das reflexões dos participantes quanto ao experimento. Fonte: Arquivo pessoal.

\begin{tabular}{|c|c|}
\hline Reflexões de A & $\begin{array}{l}\text { "Os colegas optaram por conceitos de geometria analítica para o } \\
\text { desenvolvimento da proposta de aula, estruturando-a a partir de uma história } \\
\text { muito interessante e criativa! Trata-se de uma nave que perde cinco de seus } \\
\text { tripulantes no espaço e precisam encontrar estratégias para resgatá-los. No } \\
\text { site, foram disponibilizadas as etapas de construção da atividade. Para tanto, } \\
\text { os colegas (alunos) pensaram em estratégias para resgatar cada tripulante. } \\
\text { Para cada tripulante uma nave escolhida para resgatá-lo. Daí conceitos como } \\
\text { distância entre pontos e equação de reta foram utilizados para resolução dos } \\
\text { problemas. Pudemos, na janela 3D, esboçar uma esfera representando o } \\
\text { planeta Terra e os tripulantes como pontos no espaço. No final da atividade, } \\
\text { refletimos enquanto professores em formação sobre as } \\
\text { potencialidades que esse tipo de atividade proporciona e salientamos } \\
\text { que o dinamismo e a criatividade são recursos fundamentais para } \\
\text { processos de ensino-aprendizagem." }\end{array}$ \\
\hline Reflexões de B & $\begin{array}{l}\text { "...são dados os pontos de localização dos astronautas no espaço e pede a } \\
\text { construção das superfícies quadráticas de modo que verifiquemos se é possível } \\
\text { ou não seu salvamento. Para cada astronauta, existe uma nave específica, } \\
\text { sendo única também as suas orientações. Acredito que tenha sido uma } \\
\text { atividade muito bem elaborada, pois aborda diferentes conceitos e } \\
\text { execuçóes, de nível médio para alto, mas com representações visuais } \\
\text { de grandes potencialidades para a análise dos resultados, bem como } \\
\text { desenvolvimento do aprendizado. Trabalha a autonomia, reflexão, } \\
\text { investigação e tudo de forma lúdica e representativa, fator } \\
\text { importante para um bom andamento do trabalho, pois fixa a atenção } \\
\text { e afasta a monotonia e a repetição cansativa." }\end{array}$ \\
\hline Reflexões de C & $\begin{array}{l}\text { "As atividades propostas exigiram um conhecimento prévio sobre Geometria } \\
\text { Analítica. Os professores auxiliaram quando os alunos tinham dúvidas, mas foi } \\
\text { na exploração do software que consegui relembrar os conceitos de equação de } \\
\text { reta no plano 3D e chegar nas respostas. Como comentado no item anterior, } \\
\text { na exploração do software e graças a visualização que os conceitos foram } \\
\text { relembrados e aplicados para a resolução dos problemas. Pela dinâmica e } \\
\text { apresentação do plano de aula, os alunos do ensino regular poderiam } \\
\text { ter esse contato com a atividade, até mesmo os alunos do ensino } \\
\text { fundamental. Pelo software possibilitar a visualização das } \\
\text { construções, cabe ao professor ajustar o plano de acordo com a série } \\
\text { dos alunos." }\end{array}$ \\
\hline Reflexões de D & $\begin{array}{c}\text { "Gostei bastante da proposta do grupo, que além de exigir } \\
\text { conhecimento em matemática e sobre o software, teve um caráter } \\
\text { lúdico ao usar o contexto da exploração do espaço. Acredito que usaria, } \\
\text { pois foi bem interessante participar da atividade. Os integrantes do grupo } \\
\text { mostraram dominar a atividade e as soluções, evidenciando a preparação } \\
\text { prévia e a integração do grupo." }\end{array}$ \\
\hline
\end{tabular}

Nas quatro passagens destacadas anteriormente é possível perceber o quanto os participantes, aqui renomeados por $A, B, C$ e $D$, refletem sobre o afastamento da zona de conforto pelo grupo que ministrou e gerenciou o andamento da aula. Ao propor tal atividade, o entendimento dos demais participantes da aula foi de que ao experimentar, arriscar e não controlar todas as variáveis na execução de um planejamento de aula ou atividade, o professor de matemática concentra-se numa posição de risco, sem controle sobre quais são as consequências de suas ações no decorrer da experimentação.

Logo, uma metodologia de ensino concentrada na zona de risco, de acordo com o aporte teórico apresentado no texto, além de se opor ao modelo de conforto e previsibilidade, oportuniza que o momento da aula seja centrado no sujeito, tal como mencionado pelos participantes, e torna-se necessário por parte do professor antecipações e iniciativas. Ou seja, mesmo permanecendo e 
priorizando um modelo de ensino que valorize o risco e a imprevisibilidade, é necessário por parte do professor de matemática preparo antecipado e reflexões prévias, sejam sobre o conteúdo a ser explorado ou a metodologia de trabalho a ser aplicada.

Conforme apresentado na reflexão de $B$, a noção de "autonomia, reflexão e investigação" constituem elementos importantes para uma aula. Evocando as leituras e conceitos apresentados na fundamentação teórica do presente artigo entende-se que o professor de matemática deva considerar o trinômio autonomia - reflexão - investigação um tripé necessário ao planejamento e execução de uma prática de ensino. Ao propor em sala de aula o uso de materiais e experimentar diferentes formas de explorar os conceitos, entende-se que o professor ultrapassa os limites da passividade e convida os estudantes a manipular e construir conceitos. Assim, a aprendizagem matemática torna-se um momento que vai além de manipular cálculos e expressões algébricas, ela oportuniza que por meio de reflexões individuais, que cada sujeito envolvido elabore seus próprios entendimentos sobre o mundo que o cerca.

Nota-se nas quatro reflexões grifadas na Tabela 1 uma responsabilidade atribuída ao professor quanto ao planejamento e construção da atividade. É notório observar que, tais entendimentos novamente aproximam o professor do campo reflexivo do risco. Sem a noção de risco em sala de aula, as atividades aqui apresentadas provavelmente perderiam o sentido, pois em nenhum momento elas tratam da reprodução irrestrita de conceitos ou ideias. Ao contrário, fez-se uso das tecnologias digitais e um esboço de metodologia para a abordagem de conceitos da Geometria Analítica.

Com a realização e reflexão sobre a atividade feita nota-se que em momento algum os materiais ou conduções metodológicas incitaram a noção de "velhas rotinas", tal qual na conotação exposta na fundamentação teórica e trazido por Borba e Penteado (2001). As atividades feitas procuraram permear e estimular discussões matemáticas entre todos os participantes, afastando-se da metodologia unívoca de apenas expor os conteúdos. Tal entendimento se faz necessário na presente análise, pois se tratando da formação inicial de professores de matemática, almeja-se que tal entendimento seja assimilado pelo futuro docente.

Por fim, as reflexões apresentadas na tabela incitam que tal proposta possa ser estendida para outros níveis de ensino, cabendo ao professor a realização de ajustes e reestruturações necessárias. A partir dessa projeção nota-se que a atividade aqui exposta e analisada no artigo, ocorrida na disciplina de Educação Matemática e Tecnologia, alcançou de forma plena a meta proposta no documento do plano de ensino do referido componente curricular e mencionada na introdução desse trabalho: foi oportunizado e vivenciado pelos participantes da disciplina um momento de criação e experimentação de uma prática de ensino que envolvesse o uso de materiais didáticos atrelado as tecnologias digitais e reflexões a esse respeito.

\section{CONSIDERAÇÕES FINAIS}

As ideias e debates ocorridos na disciplina de Educação Matemática e Tecnologia em 2017/1 oportunizaram que tal proposta se concretizasse primeiramente na forma de criação, execução de uma atividade e após, reflexões na forma de um artigo. O grupo envolvido na criação e execução da aula concordou e aceitou o desafio de criar uma proposta metodológica para o ensino de matemática que se afastasse da zona de conforto. Almejava-se criar um plano de aula em que a apresentação do software Winplot e sua utilização para resolução de cálculos matemáticos não fosse o foco principal 
do planejamento. Entendia-se como necessário ir além e propor algo que oportunizasse aos participantes um entendimento sobre utilização do software Winplot e que também tivesse relação e aplicação com a matemática.

A partir do questionamento: "como sair da zona de confronto e propor uma atividade que atenda as expectativas e mobilize discentes para o entendimento do software, propiciando que este seja objeto de reflexão por parte do aluno e, que com isso ele possa ser utilizado futuramente nas atividades profissionais" construiu-se a problemática exposta no artigo. Entende-se que a proposta aqui relatada e ancorada nos aporte teórico e revisões de literatura não esteja encerrada. Trata-se de um contínuo exercício de formação permanente do professor de matemática, que tanto reflete e age, num movimento biunívoco, no decorrer da prática profissional.

Almeja-se como projeção e perspectiva para o trabalho que o artigo seja entendido como um convite ao leitor/professor de matemática. Quanto aos objetivos inerentes ao alcance da proposta entendese que sejam: estimular a criação e uso de materiais inéditos para a prática docente, incitar reflexões sobre metodologias de ensino que valorizem a autonomia, reflexão e investigação em sala de aula e, que a formação docenteseja entendida como um exercício permanente, iniciado na formação inicial e estendendo-se por toda a vida profissional do professor de matemática.

\section{REFERÊNCIAS}

ANDRADE, Vladimir Lira Veras Xavier De; RÉGNIER, Nadja Maria Acioly; ANDRADE, Paula Virgínia Chaves Cabral. Utilização de um dispositivo pedagógico envolvendo histórias em quadrinhos na formação de professores na França: o lugar da matemática em situações-problema evocadas pelos estudantes. Revista Espaço Pedagógico. Passo Fundo (RS), v.20, n.1, p136-157. 2013. Disponível em: <http://seer.upf.br/index.php/rep/article/view/3512/2297> Acesso em fevereiro de 2018.

BORBA, Marcelo de Carvalho; PENTEADO, Miriam Godoy. Informática e Educação Matemática. 1.ed. Belo Horizonte: Autêntica, 2001.

CUNHA, Igor Guilherme da. Liga matemática: uma história em quadrinhos interativa. Porto Alegre: UFRGS, 2009. Trabalho de Conclusão de Curso de Graduação em Licenciatura em Matemática. Instituto de Matemática e Estatística, Universidade Federal do Rio Grande do Sul, 2009. Disponível em: <http://hdl.handle.net/10183/23718> Acesso em fevereiro de 2018.

LOURENÇO, Jobson Darlan Martins. 0 uso do aplicativo Winplot para resolver problemas de aplicação sobre a função quadrática. Trabalho de Conclusão de Curso. Licenciatura em Matemática. Universidade Estadual da Paraíba, Campina Grande, 2017. Disponível em < http://dspace.bc.uepb.edu.br/jspui/handle/123456789/15523 >Acesso em fevereiro de 2018.

MISKULIN, Rosana GiarettaSguerra; AMORIN, Jonide Almeida; SILVA, Mariana da Rocha Corrêa. Histórias em quadrinhos na aprendizagem da matemática. In: IX Encontro Gaúcho de Educação Matemática. Caxias do Sul (RS). 2006. Disponível em: < http://miltonborba.org/CD/Interdisciplinaridade/Encontro Gaucho Ed Matem/cientificos/CC45.pdf> Acesso em fevereiro de 2018.

MORAES, Priscila. Hqs e matemática. Porto Alegre: UFRGS, 2009. Trabalho de Conclusão de Curso de Graduação em Licenciatura em Matemática. Instituto de Matemática e Estatística, Universidade Federal do Rio Grande do Sul, 2009. Disponível em: <http://hdl.handle.net/10183/23717> Acesso em fevereiro de 2018. 
PARMEGIANI, Roselice. A história da matemática em quadrinhos. In: IV Jornada Nacional de Educação Matemática e XVII Jornada Regional de Educação Matemática. Passo Fundo (RS). 2012. Disponível em: < http://anaisjem.upf.br/download/de-23-parmegiane.pdf> Acesso em fevereiro de 2018.

PEREIRA, Ana Carolina Costa. O uso de quadrinhos no ensino da matemática: um ensaio com alunos de licenciatura em matemática da UECE. In: X Encontro Nacional de Educação Matemática (ENEM). Salvador (BA). 2010.2 Disponível em: <http://www.lematec.net.br/CDS/ENEM10/artigos/RE/T18 RE1739.pdf> Acesso em fevereiro de 2018.

RICHIT, Andriceli.; SILVA, Rodrigo Sychocki da. Superfícies quádricas e TIC's: concepção, aplicação e análise de uma proposta didática à luz da teoria da representação semiótica de Duval. \# Tear: Revista de Educação Ciência e Tecnologia, Canoas, v.3, n.2, 2014. Disponível em: $<$ https://periodicos.ifrs.edu.br/index.php/tear/article/view/1865 > Acesso em fevereiro de 2018.

SILVA, Adriano; SANTOS, Luciana; SOARES, Willames. A. Utilização do Winplot Como Software Educativo Para o Ensino de Matemática. Revista Diálogos. Revista de Estudos Culturais e da Contemporaneidade. Garanhuns (PE). 2012. Disponível em: <http://www.revistadialogos.com.br/Dialogos 6/Dialogos 6 Willames Adriano Luciana.pdf> Acesso em fevereiro de 2018.

SILVA, Warley Gramacho da. Aplicando o Software Winplot para o Ensino de Sistemas Lineares.Revista EaD\& Tecnologias Digitais na Educação. Universidade Federal da Grande Dourados. v. 5, n. 7. Grandes Dourados (MS). 2017. Disponível em: < http://ojs.ufgd.edu.br/index.php/ead/article/view/7191> Acesso em fevereiro de 2018.

UFRGS. Universidade Federal do Rio Grande do Sul. Plano de Ensino da disciplina de Educação Matemática e Tecnologia (MAT01074). 2017. 